\title{
Registros da maratona em J ogos Olímpicos para a difusão em aulas de Educação Física
}

\author{
CDD. 20.ed. 796.08 \\ 796.426 \\ 796.48
}

\author{
Sara Quenzer MATTHIESEN* \\ Guy GINCIENE* \\ Fernando Paulo Rosa de FREITAS ${ }^{*}$ \\ *Instituto de Biociên- \\ cias, Universidade \\ Estadual Paulista-Rio \\ Claro. \\ **Secretaria da Edu- \\ cação do Estado de \\ São Paulo.
}

\begin{abstract}
Resumo
Pautada em pesquisa documental, o objetivo desse trabalho consistiu em investigar as alterações pelas quais a maratona passou ao longo dos anos, visando a difusão desse conhecimento, especialmente, em aulas de Educação Física. Entre as modificações estruturais, os atletas, as marcas e as curiosidades em torno de cada uma das edições olímpicas dessa prova, verificou-se, por exemplo, que inspirada em uma lenda grega, a prova da maratona foi incluida na programação dos Jogos Olímpicos Modernos, no masculino, em 1896 e no feminino, em 1984; foi disputada em distâncias e percursos diferentes e instaurou novas regras, a exemplo da "Norma Scheiss". Se esses são alguns dos aspectos identificados por essa pesquisa, outros também devem ser evidenciados, considerando que a história do esporte é um dos conteúdos que deveria ser ensinado em aulas de Educação Física.
\end{abstract}

UnITERMOS: Maratona; História do esporte; Educação física; Corrida.

\section{Introdução}

Não há, como veremos, dúvida de que a história do esporte é um dos conteúdos que deveriam ser ensinados em aulas de Educação Física. Entretanto, referindo-nos ao atletismo, constatamos, com base em Faganello (2008), que, na maioria das vezes, sua história se restringe a breves parágrafos em livros voltados aos seus aspectos técnicos, normativos ou de treinamento, sem que haja um aprofundamento sobre as modificações que ocorreram em cada uma de suas provas. Alguns, a atrelam às necessidades de sobrevivência (BRASIL, 1981), enquanto outros preferem tratar da história esportiva dessa modalidade com base em registros que nos remetem à Grécia Antiga (Brasil, 1984). Há, também, aqueles que como PaIOli (1945) e ConfederaçÃo Brasileira de Atletismo - CBAt (2000) referem-se à história documental do atletismo, com registros de quando começou a ser praticado no Brasil; quais as principais competiçóes, além de mostrar os resultados em determinados períodos. Por outro lado, livros como os da ConFEDERAÇÃo Brasileira de ATLETismo $(1995,2001)$ se detém àquilo que poderíamos considerar como a história institucional do atletismo, já que partem da organização da IAAF (Associação Internacional das Federaçóes de Atletismo), remetendo-se a esta organização e às outras instituições que, atualmente, regem e regulamentam o atletismo mundialmente.

Além desses, há livros que tratam da história particular de alguns atletas, como é o caso de RuBio (2004) que se remete a atletas que participaram dos Jogos Olímpicos; de PAIOLI (1949) que se refere aos atletas vitoriosos; da ConfederaÇão BRASILEIRA DE Atletismo (2001) que se remete à participação feminina ou D'ÂNGELO (2007) que registra peculiaridades da trajetória de Vanderlei Cordeiro de Lima.

Se essa é a constatação advinda de pesquisa em livros nacionais de atletismo, observamos, por outro lado, publicações mais recentes no campo da Educação Física Escolar brasileira que enaltecem a importância do conhecimento histórico, como é o caso de: DARIDO e RANGel (2005), dos Parâmetros Curriculares Nacionais - PCNs (BRASIL, 1998) - e da Proposta de Educação Física do Estado de São Paulo (SÃo Paulo, 2008a, 2008b, 2008c).

Enfim, se há um reconhecimento, por parte de referências na área da Educação Física Escolar, de 
que a história do esporte constitui-se em um dos conteúdos a serem ensinados em aulas de Educação Física, o que, exatamente, deveria ser ensinado?

Nos dois primeiros casos, o conhecimento histórico aparece como parte da dimensão conceitual dos conteúdos a serem trabalhados pela Educação Física Escolar, de modo a levar o aluno a conhecer "as mudanças pelas quais passaram os esportes" (DARIDO \& RANGEL, 2005, p.66). Entretanto, como orienta MATTHIESEN (2007), o aluno pode aprender a história do esporte - no caso, do atletismo -, vivenciando as transformaçôes pelas quais passou cada uma de suas provas, a exemplo do que fez Freitas (2009), em relação à prova do salto com vara.

Também preocupados com os rumos da Educação Física, o Governo do Estado de São Paulo elaborou em 2008, uma proposta para o seu ensino no Ensino Fundamental, na qual o processo histórico está relacionado a diferentes conteúdos em 13 dos 16 planejamentos bimestrais do Ensino Fundamental e mais duas vezes no Ensino Médio (Freitas, 2009), não deixando em dúvidas acerca da importância do ensino desse conteúdo em aulas de Educação Física.

Vejamos com mais detalhes o que isso significa. Analisando o "Caderno do Professor" observamos que, para o desenvolvimento das corridas rasas, no $1^{\circ}$ bimestre das $6^{\text {a }}$ série, os alunos devem realizar pesquisas na "internet e em outras fontes (indicadas ou não pelo professor) sobre o processo histórico do atletismo, a evolução técnica e as regras [...]" (SÃo Paulo, 2008a, p.13). Já no "Caderno do Professor" da $7^{a}$ série, do $1^{\circ}$ bimestre (SÃo PaUlo, 2008b), a sugestão é que se trabalhe com o atletismo de forma integrada com a disciplina de História, desenvolvendo-se um trabalho interdisciplinar entre os professores dessas disciplinas, facilitando aos alunos "[...] a compreensão dos conteúdos de forma mais global e integrada [...]" (p.11).

\section{Método}

Com base em fontes documentais, essa pesquisa teórica, caracterizada como uma pesquisa bibliográfica refere-se ao tema "a partir de referências teóricas publicadas em documentos" (CERVO \& Bervian, 2002, p.65). Nesse sentido, concentrou-se na coleta de dados provenientes de livros, artigos, imagens e "websites" relacionados à história da maratona desde sua origem lendária na Grécia Antiga até sua inserção na programação dos Jogos Olímpicos Modernos, considerando-se a
Assim, o "processo histórico" deveria ser trabalhado de acordo com o conteúdo de diferentes bimestres e em diferentes modalidades esportivas. Por exemplo, o "processo histórico" deveria ser trabalhado no $2^{\circ}, 3^{\circ}$ e $4^{\circ}$ bimestres da $5^{a}$ série (SĀO PaUlo, 2008c, p.49); no $1^{\circ}$ bimestre da $6^{a}$ série especificamente como "história do atletismo" e no $2^{\circ}, 3^{\circ}, 4^{\circ}$ bimestres como "processo histórico" de outras modalidades (SÃO PAULO, 2008c, p.50); no $1^{\circ}$ bimestre da $7^{\mathrm{a}}$ série esse conhecimento aparece como "história do atletismo", enquanto que no $3^{\circ}$ e $4^{\circ}$ bimestres como "processo histórico" de outras modalidades (SÃo PaUlo, 2008c, p.51); e no $1^{\circ} \mathrm{e}$ $3^{\circ}$ bimestres da $8^{a}$ série esse conhecimento aparece como "processo histórico". Além disso, a inserção do "processo histórico" dentre o conteúdo proposto para os $1^{\circ}$ bimestres da $2^{a}$ e $3^{a}$ série do Ensino Médio também se fazem presentes (SÃo PAULO, 2008c), mas sem que haja maiores indicações bibliográficas que dêem suporte ao trabalho do professor. Em outras palavras, perguntaríamos: Ora, se as referências bibliográficas voltadas ao ensino da história do esporte - em especial do atletismo - são restritas e, praticamente, desconhecidas, como pode se exigir que o professor trabalhe com a história do atletismo em aulas de Educação Física?

Considerando ser essa uma lacuna na área e visando reunir elementos capazes de contribuir para o trabalho do professor, aprofundamos na história do atletismo ${ }^{1}$, optando, nesse artigo, pela maratona, cuja origem lendária e características próprias contribuiu para que se tornasse uma das provas mais representativas do atletismo no mundo contemporâneo.

Assim o objetivo deste estudo foi investigar as alteraçóes pelas quais a maratona passou ao longo dos anos, reunindo subsídios para a difusão desse conteúdo, especialmente, em aulas de Educação Física.

importância dessa prova no cenário esportivo mundial.

Assim, considerando que uma pesquisa bibliográfica visa "conhecer e analisar as contribuiçōes culturais ou científicas do passado existentes sobre um determinado assunto, tema ou problema" (CERVO \& BERVIAN, 2002, p.65), aprofundamos os estudos sobre a maratona, a fim de reunir elementos que possam contribuir para a difusão desse conhecimento, especialmente, em aulas de Educação Física. 


\section{Resultados e discussão}

Dentre os aspectos que, certamente, deveriam ser referendados quando do ensino da história da maratona em aulas de Educação Física, estão aqueles que se remetem à sua origem. Diz a lenda que quando os gregos derrotaram os invasores persas em uma batalha na planície de Maratona, em 490 a.C., o general Milcíades destacou um soldado de sua tropa para que retornasse a Atenas a fim de comunicar a vitória ao seu povo. O escolhido foi o soldado e atleta Pheidippides, o qual, após correr os aproximados $40 \mathrm{~km}$ entre o local da batalha e Atenas, só teve forças para dar a notícia dizendo "vencemos", caindo morto em seguida (LANCELLOTTI, 1996).

Assim, diferente do que muitos podem pensar, a maratona só passou a integrar a programação olímpica em 1896, a partir da sugestão de Michel Bréal ao Barão de Coubertein de reviver o feito de Pheidippides, mas, obviamente, evitando que alguém morresse a exemplo do que lhe teria acontecido, razão pela qual provas-testes foram realizadas.

Em Atenas-1896, nos I Jogos Olímpicos Modernos, a maratona, então, com cerca de 40 $\mathrm{km}$, teve vários inscritos. Para LANCELlotTI (1996) teriam sido 17, dos quais 13 eram gregos. NogUeIrA (2002) enfatiza que poderiam ter sido 18, 21 ou 25 , ainda que considere que alguns dos gregos não estavam oficialmente inscritos, além do que muitos, prevendo as dificuldades, não compareceram. Outros, a exemplo do americano Arthur Blake e do australiano Edwin Flack que chegaram a liderar a prova, desistiram ao chegarem aos 23 e $37 \mathrm{~km}$, respectivamente, sendo que apenas nove completaram o percurso (Nogueira, 2002).

Descrevendo detalhes dessa prova, que poderiam, a nosso ver, integrar os conhecimentos a serem difundidos em aulas de Educação Física, LANCELlotTi (1996) ressalta que os prêmios foram: uma taça de prata oferecida por Bréal e uma ânfora de quase 2.000 anos oferecida pelo principal patrocinador, Georgios Averoff, enquanto que o tiro de largada teria sido dado com uma arma de verdade do major e diretor da prova Anastasios Papadiamantopoulos, que seguiu os competidores a cavalo por toda a corrida.

Se esses são alguns dos aspectos identificados em torno da origem da maratona, outros, a exemplo das modificaçôes que veremos, também devem integrar, o conteúdo a ser veiculado em aulas de Educação Física.

\section{Sobre as modificações na maratona em J ogos Olímpicos}

Foram várias as modificações que ocorreram na maratona desde quando foi inserida em Jogos Olímpicos, as quais merecem ser amplamente difundidas. Comecemos pela distância da prova. Primeiramente, e como fruto de uma homenagem à lenda grega, a maratona foi disputada num percurso de $40 \mathrm{~km}$, entre as cidades de Maratona e Atenas, nos I Jogos Olímpicos Modernos, em 1896.

Em Paris-1900, passou a ter $40.260 \mathrm{~m}$, enquanto que em St. Louis-1904, os $40.000 \mathrm{~m}$ foram utilizados novamente como distância oficial. Em Londres-1908, adotou-se os atuais $42.195 \mathrm{~m}$, sendo que o acréscimo de $2.195 \mathrm{~m}$ ocorreu para que a linha de chegada ficasse em frente ao camarote real, no Estádio Olímpico de White City, onde estaria a rainha Alexandra, da Inglaterra e "um batalhão de aristocratas" (LANCellotti, 1996, p.48). A distância de 42.192 m, no entanto, não se tornou oficial de imediato, já que em Estocolmo-1912 e na Antuérpia-1920 essa metragem não foi utilizada, adotando-se a distância de 42.200 $\mathrm{m}$ e $42.750 \mathrm{~m}$, respectivamente.

Ao que consta a distância da maratona foi oficializada pela IAAF em 1921 (WIKIPEDIA, 2010a) de modo que apenas em Paris-1924, é que os 42.195 $\mathrm{m}$ voltaram a ser utilizados, mantendo-se até os dias de hoje como distância oficial, com o que concorda LANCELLOTTI (1996).

No que se refere à classificação da prova, é interessante destacar que a regra atual (CBAt, 2006, p.31), difere das regras das décadas de 80 e de 90 , quando não se utilizava a denominação de "corridas de rua", mas "corrida rústica", também conhecida como pedestrianismo (CBAt, s.d., p.18). Naquela época, a regra específica para esse tipo de prova era a "regra 165" composta por apenas cinco itens (CBAt, 1967-1968, p.54), incorporados às ediçôes posteriores. Atualmente, a "regra 240" e seus 10 detalhados itens (CBAt, 2006, p.286-90) normatizam essa prova, cujas regras foram sendo modificadas pouco a pouco em função de suas necessidades.

LANCELlotTi (1996) enfatiza que dentre as primeiras maratonas olímpicas, a de Londres-1908, foi a mais organizada, inclusive para se evitar o encurtamento proposital do percurso ou auxílios não 
permitidos que teriam ocorrido em outras edições. O exemplo mais conhecido é o dos Jogos Olímpicos de 1904, quando Fred Lorz correu apenas $15 \mathrm{~km}$ do percurso, após o qual teria pego uma carona até o $\mathrm{km}$ 32. Revelada a fraude, a medalha de ouro foi dada a Thomas Hichs, registrado como vencedor da prova.

É interessante observar que, algumas vezes, há no próprio trajeto da maratona, inconveniências. Foi o caso da maratona de Paris-1900, disputada num percurso que parece ter dificultado seu acompanhamento, com quatro voltas numa pista improvisada e passagens por becos e desvios até retornar ao parque onde havia sido dada a partida (LANCELLOTTI, 1996). Em função de situações como essas, em 1908 "delimitaram com cordas e com guardas o trajeto da competição, ruas e avenidas apropriadamente calçadas" (LANCELLOTTI, 1996, p.48). Isso, certamente, contribuiu para que os atletas não "cortassem caminho", como foi acusado o francês Michel Théato na maratona de Paris-1900. Atualmente, a regra prevê a desclassificação nos casos em que o atleta encurtar o percurso, de modo que um árbitro ou Inspetor devem:

[...] permanecer no local designado pelo Árbitro

Geral, observando atentamente o desenrolar da prova, e, no caso de uma falha ou violação das Regras [...] por um atleta ou outra pessoa, fazer um registro por escrito imediato do ocorrido para o Árbitro Geral (CBAt, 2006, p.135-6).

Também, para que se conheça melhor algumas das particularidades da prova tal qual ela ocorre atualmente, é importante evidenciar que hoje a maratona deve ocorrer na rua, sendo que, no caso de tráfego intenso, poderá ser realizada em pista de bicicleta ou de pedestre, ao longo da rua, em percurso devidamente marcado, mas nunca "sobre terreno macio como gramado ou similar", ainda que a "saída" e a "chegada" possam ser "no estádio" (CBAt, 2006, p.286). Isso evitaria o que ocorreu, por exemplo, na maratona de St. Louis-1904, disputada numa estrada de terra, com péssimas condições em função da poeira provocada por aqueles que a acompanhavam. Também, por questôes de segurança, a regra prevê que: "O Comitê Organizador deve assegurar que as ruas usadas na competição estejam fechadas para tráfego motorizado em todas as direções" (CBAt, 2006, p.289).

Se essas são algumas das modificações da maratona olímpica que poderiam integrar o conhecimento a ser veiculado, especialmente, em aulas de Educação Física, há outras que merecem ser destacadas. Em Paris-1900, por exemplo, torcedores puderam refrescar os 13 inscritos com "mangueiradas de água fresca”, lembra LANCELlOTTI (1996, p.18). Em outras edições, como a dos Jogos Olímpicos de St. Louis-1904, havia um único ponto em que os atletas poderiam se refrescar com água, um poço público, localizado no último terço do percurso" (p.33)", enquanto que em Estocolmo-1912, havia uma "barraquinha com água, refrescos e outros líquidos de reposição", lembra LANCELLOTTI (1996, p.68).

Outro caso que merece ser destacado é o de Thomas Hichs, nos Jogos Olímpicos de 1904, quando recebeu de seus acompanhantes - que foram autorizados pelo médico da organização -, "tabletes de sulfato de estricnina, ovos crus e lautos goles de conhaque", já que nos últimos $15 \mathrm{~km}$ quis desistir duas vezes (LANCELlotTI, 1996, p.34). Um outro caso de ingestão de bebida alcoólica, foi o de Hefferon, em Londres-1908, lembra LANCELOTTI (1996), que "aceitou, inexplicável e tolamente, um gole de champanha de um torcedor" (p.48).

Nos dias de hoje, deve haver "postos de abastecimento aproximadamente em cada $5 \mathrm{~km}$ " da maratona, além de "postos de bebidas/esponjas e água" localizados "aproximadamente na metade do caminho entre os postos de abastecimento, ou com mais frequência se as condiçôes climáticas assim exigirem" (CBAt, 2006, p.289).

Para que a ingestão indevida de líquido não ocorra durante a prova, a regra atual prevê que haja outros "refrescos apropriados", os quais devem ser providenciados pelo Comitê Organizador da prova ou pelos atletas, sendo que ficarão em postos indicados pelo competidor, e serão entregues a eles por pessoas autorizadas, sob pena de punição caso isso ocorra de forma não prevista pela regra. Ou seja: "Um atleta que tome refrescos em um outro lugar qualquer senão nos postos de abastecimento estará passível de desclassificação" (CBAt, 2006, p.290).

Outra situação que já foi motivo de desclassificação e que merece ser mencionada foi o auxílio dado para que os atletas conseguissem completar a prova, a exemplo do que aconteceu com o italiano Dorando Pietri. Nesse caso específico, há registros que evidenciam que ao longo da maratona de Londres-1908, foram várias as mudanças na liderança da prova, até que Dorando Pietri, assumiu a primeira posição ultrapassando o sul-africano Hefferon que, em seguida, foi também ultrapassado pelo americano John Joseph Hayes. Contudo, as chances de Hayes ganhar a prova eram praticamente nulas, uma vez que Dorando Pietri havia adentrado o estádio com mais de um minuto de vantagem. Entretanto, esse esforço final não foi sem consequências para Pietri que parecia não se sentir muito bem ao adentrar o estádio, já que virou à esquerda e não à direita como deveria, 
chegando ao limite de suas forças para concluir os $300 \mathrm{~m}$ finais. Depois de cair algumas vezes e embora tenha alegado ter condiçôes de terminar a prova, foi ajudado por fiscais, como Jack Andrew, sem se darem conta do "regulamento, que vedava qualquer ajuda aos competidores" (LANCELLOTTI, 1996, p.48).

Referindo-se a esse episódio, LANCELLOTTI (1996) destaca que mesmo estando em uma maca, Dorando Pietri se defendeu dizendo: "Eu não pedi que me apoiassem. Poderia ter completado a prova sozinho" (p.49). Entretanto, para não se comprometer ainda mais, o fiscal Jack Andrew solicitou que o atleta fosse examinado por um médico que constatou que: "sem o suporte de Andrew, seria inevitável o colapso", fato que o levou à desclassificação (LANCELLOTTI, 1996, p.49). Barbosa (1979) argumenta que a conduta correta seria desclassificá-lo de imediato, fato que ocorreu horas depois ao se declarar John Joseph Hayes como vencedor da prova.

$\mathrm{Na}$ estreia feminina em maratonas olímpicas em 1984, um episódio semelhante acabou modificando essa regra. Vinte minutos após a vencedora Joan Benoit cruzar a linha de chegada, a suíça Gabriela Andersen-Scheiss apareceu cambaleando na pista do Coliseum de Los Angeles, praticamente se arrastando para completar os $42.195 \mathrm{~m}$. Para que se tenha uma ideia, essa atleta demorou $5 \mathrm{~min} 44 \mathrm{~s}$ para percorrer os 100 m finais, pontua LANCELLOTTI (1996).

Apesar da temperatura e prestes a desmaiar, Andersen-Scheiss, aos 39 anos, se recusou a desistir da prova, terminando-a, na $37^{a}$. colocação, fato que lhe rendeu o apelido de Great Gaby e provocou uma modificação no regulamento. A "Norma Scheiss", como é conhecida, determina que “(...) em casos equivalentes, os médicos poderiam automaticamente se aproximar do corredor ou da corredora em dificuldades físicas para um exame de seu estado, sem o risco de desclassificarem o atleta" (LANCELlotTi, 1996, p.549), como ocorria até então. Assim, atualmente: "Um exame médico dentro do percurso, durante o desenrolar de uma prova, realizado por equipe médica designada, e claramente identificada pelo Comitê Organizador, não será considerado como ajuda (CBAt, 2006, p.289).

Certamente, a "Norma Scheiss" contribuiu para que as maratonas passassem a ser mais seguras e isso deve ser sempre lembrado. Antes disso, houve, inclusive, registro de morte, como foi o caso do português Francisco Lázaro (1891-1912) que morreu poucas horas após ter abandonado a maratona de Estocolmo-1912 (Wikipedia, 2010b). Ainda hoje, casos de morte, muitas vezes, são inevitáveis, em virtude do grande número de participantes e da combinação de problemas prévios de saúde e/ou do esforço da prova.

Entre as regras que interferem diretamente na performance do atleta, a que se remete aos "uniformes, sapatos e números” é bastante curiosa. Observando imagens de outros tempos nota-se que os trajes utilizados pelos atletas eram os mais diversos, indo desde "shorts" mais longos até o uso de suspensórios, a exemplo de Spiridon Louis em Atenas-1896. Atualmente, a regra prevê que o uniforme não deve ser transparente, nem dificultar a visão do árbitro, deve estar limpo, ser da mesma cor na frente e nas costas onde deve estar afixado o número que identifica o atleta (CBAt, 2006, p.149-50). Entretanto, no que se refere aos calçados, atualmente os atletas podem competir: "[...] descalços ou calçados em um ou em ambos os pés”, de forma que os mesmos não dêem quaisquer vantagens adicionais aos competidores (CBAt, 2006, p.150). O exemplo mais conhecido de um atleta que colocou essa regra em prática é o do etíope Abebe Bikila, que venceu a maratona de Roma1960, correndo descalço, sendo que em Tóquio-1964 a venceu calçado com tênis.

\section{Sobre a participação dos atletas em maratonas olímpicas}

São várias e interessantes as particularidades em torno dos atletas que disputam essa prova, que merecem ser conhecidas, afinal, desde os Jogos Olímpicos de Atenas-1896 até os de Pequim-2008, foram 25 as maratonas disputadas pelos homens em 25 ediçóes dessa competição. Nesse sentido, foram 23 os atletas, de 14 países a conquistarem a primeira colocação nessa prova ao longo dos anos, considerando os bicampeonatos do etíope Abebe Bikila (1960-1964) e do alemão oriental Waldemar Cierpinski (1976-1980).

Em Atenas-1896, o grego Spiridon Louis foi, como vimos, o vencedor da maratona com o tempo de $2 \mathrm{~h} 58 \mathrm{~min} 50 \mathrm{~s}$. Na edição seguinte, em Paris-1900, o francês Michel Théato venceu a prova em 2 h59min 45 s, embora, como vimos, tenha sido acusado de encurtar o percurso. Em St. Louis-1904, foi a vez do americano Thomas Hicks conquistar o ouro em 3h28min53s. Em Londres-1908, a maratona consagrou o americano Johnny Hayes, como vencedor da prova em $2 \mathrm{~h} 55 \mathrm{~min} 18 \mathrm{~s}$, enquanto que em Estocolmo-1912, foi a vez do sul-africano Kenneth McArthur vencer a maratona em $2 \mathrm{~h} 35 \mathrm{~min} 56 \mathrm{~s}$. Depois disso, a maratona olímpica, em função da suspensão da edição de 1916 devido a I Guerra Mundial, foi disputada novamente em 1920, ocasião em 
que o finlandês Hannes Kolehmainen, a venceu em 2h32min35s. Em Paris-1924, o também finlandês Albin Stenroos, venceu a maratona em 2h41 min22s, enquanto que em Amsterdam-1928, o francês Boughera El Ouafi a venceu em 2h32min57s. Em 1932, pela primeira vez, um sul-americano conquistou o ouro na maratona. Foi o argentino Juan Carlos Zabala, que em $2 \mathrm{~h} 31 \mathrm{~min} 36 \mathrm{~s}$, venceu a maratona de Los Angeles. Em Berlin-1936, foi a vez do chinês Sohn Kee-Chung vencer a prova em $2 \mathrm{~h} 29 \min 16 \mathrm{~s}$.

Com a não realização dos Jogos Olímpicos em 1940 e 1944, a maratona somente foi disputada em Londres-1948, ocasião em que o argentino Delfo Cabrera a venceu em 2h34min51s. Em Helsinque-1952, o tcheco Emil Zatopek venceu, entre outras provas, a maratona, em $2 \mathrm{~h} 23 \mathrm{~min} 03 \mathrm{~s}$, sendo que em Melbourne-1956 foi superado pelo francês Alain Mimoun que a venceu em 2h25min00s.

Por sua vez, o etíope Abebe Bikila foi o primeiro a vencer a maratona em dois Jogos Olímpicos, isto é, em Roma-1960 e Tóquio-1964, em 2h15min16s e $2 \mathrm{~h} 12 \mathrm{~min} 11 \mathrm{~s}$, respectivamente. Também etíope, Mamo Wolde venceu a maratona dos Jogos Olímpicos do México-1968, em 2h20min26s, sendo que em Munique-1972, foi a vez do americano Frank Shorter consagrar-se campeão em $2 \mathrm{~h} 12 \mathrm{~min} 19 \mathrm{~s}$. Mais tarde, o alemão oriental Waldemar Cierpinski também conseguiu vencer duas maratonas olímpicas: em Montreal-1976, com 2h09min55s e em Moscou-1980, com 2h11min03s. Em Los Angeles-1984, o português Carlos Lopes venceu a maratona em 2h09min21s. Em Seul-1988, foi a vez do italiano Gelindo Bordin vencêla em 2h10min32s, enquanto que em Barcelona-1992, o sul-coreano Young-Cho Hwang venceu a prova em 2h13min23s. Em Atlanta-1996, o sul-africano Josia Thugwane venceu a maratona em $2 \mathrm{~h} 12 \mathrm{~min} 36 \mathrm{~s}$ e em Sydney-2000, foi a vez do etíope Gezahegne Abera vencê-la em $2 \mathrm{~h} 10 \mathrm{~min} 11 \mathrm{~s}$. Já as duas últimas maratonas em Jogos Olímpicos foram vencidas, respectivamente, pelo italiano Stefano Baldini, em 2h10min55s em Atenas-2004, enquanto que em Pequim-2008, o vencedor foi o queniano Samuel Wanjiru (atual recordista olímpico), com o tempo de $2 \mathrm{~h} 06 \mathrm{~min} 32 \mathrm{~s}$. Vale, ainda, mencionar, que o queniano Haile Gebrselassie é o atual recordista mundial da prova, com $2 \mathrm{~h} 03 \mathrm{~min} 59 \mathrm{~s}$, conquistado em 28.09.2008.

Quanto aos maratonistas brasileiros, foram poucas as participações se comparadas às 25 edições olímpicas da prova. Segundo LANCELLOTTI (1996), os primeiros brasileiros a participarem de uma maratona olímpica foram Matheus Marcondes que, infelizmente, não concluiu a prova em Los Angeles-1932 e João
Clemente da Silva, o $19^{\circ}$ colocado dentre os 20 que a concluíram. Depois deles, só localizamos registros ${ }^{2}$ de maratonistas em Jogos Olímpicos a partir de 1984, quando Eloy Schleder conquistou a 23a colocação. Em Seul-1988, Ivo Machado Rodrigues ficou na 56a colocação enquanto que Diamantino Silveira dos Santos ficou com a $48^{a}$ colocação. Em Barcelona-1992, Osmiro de Souza Silva ficou em $24^{\circ}$ lugar, Joseíldo Rocha da Silva com o $56^{\circ}$ lugar e Diamantino dos Santos não concluiu a prova. Em Atlanta-1996, Diamantino dos Santos ficou em $73^{\circ}$ lugar, Luiz Antônio dos Santos em 10 e Vanderlei Cordeiro de Lima em 47․ Em Sydney-2000, foram três os maratonistas brasileiros: Éder Fialho e Osmiro de Souza Silva não concluíram a prova na qual Vanderlei Cordeiro de Lima ficou com o 75 lugar. Em Atenas-2004, Vanderlei Cordeiro de Lima, tornou-se o único brasileiro a conquistar uma medalha olímpica na maratona, mesmo após ter sido derrubado por um padre irlandês quando liderava a prova. Acabou conquistando a $3^{a}$ colocação, com o tempo de $2 \mathrm{~h} 12 \mathrm{~min} 11 \mathrm{~s}$, sendo recompensado com a medalha Barão de Coubertin pelo espírito olímpico demonstrado ao superar o inesperado e ter concluído a prova. Nessa mesma edição André Luiz Ramos não completou a maratona, assim como Rômulo Vagner da Silva. Na edição seguinte em Pequim2008, participaram da maratona os brasileiros: Frank Caldeira, Marilson Gomes dos Santos e José Teles de Souza. Embora os dois primeiros não tenham concluído a prova, José Teles de Souza concluiu o percurso na $38^{\text {a }}$ colocação (MBPREss, 2010).

Ainda que não tenha obtido esse resultado em uma maratona olímpica, vale mencionar que o Brasil já teve um recordista mundial nessa prova. Trata-se de Ronaldo da Costa, que em 20/09/1998, concluiu a Maratona de Berlin em 2h06min05s, ainda hoje, o melhor tempo de um brasileiro nessa prova.

E quanto à participação feminina? Ainda que em Jogos Olímpicos a inclusão da maratona feminina tenha ocorrido tardiamente na programação do atletismo, há registros sobre a participação das mulheres em provas de maratona desde 1926. Lawson (1997) aponta Violet Piercy (GBR) como a primeira a registrar a melhor marca mundial da maratona feminina, ao completar a prova com o tempo de $3 \mathrm{~h} 40 \mathrm{~min} 22 \mathrm{~s}$, no dia 3 de outubro de 1926, em Londres.

Outros, entretanto, atribuem à americana Kathrine Switzer a quebra do tabu de que as mulheres eram incapazes de correr a maratona, isto é, de que "não tinham força e resistência para correr os 42.195 metros", ao completar a Maratona de Boston, 
"disfarçada" entre os homens (ESPN, 2010). De qualquer forma, LAWSON (1997) ressalta que entre 1963 e 1983 foram 23 os melhores tempos femininos registrados nessa prova, de modo que, até um ano antes da primeira participação feminina em maratonas olímpicas, muitas foram as participações das mulheres nesse tipo de prova. Entretanto, não é demais lembrar que a estreia das mulheres no atletismo olímpico ocorreu em Amsterdam-1928, quando participaram das provas: $100 \mathrm{~m}$ rasos, $800 \mathrm{~m}$ rasos, revezamento $4 \times 100 \mathrm{~m}$, salto em altura e lançamento do disco, de modo que a maratona passou a integrar o atletismo olímpico 54 anos mais tarde, em 1984.

Nessa ocasião, já com a distância oficial de 42.195 m, 28 países participaram da maratona feminina, num total de 50 inscritas, sendo que a primeira colocada foi a americana Joan Benoit, com o tempo de $2 \mathrm{~h} 24 \mathrm{~min} 52 \mathrm{~s}$. Nos Jogos Olímpicos seguintes, em Seul-1988, a portuguesa Rosa Mota venceu a prova em 2h25min39s. Em Barcelona-1992, a russa Valentina Yegorova, venceu a maratona em 2h32min41s. Em Atlanta-1996, foi a vez da etíope Fatuma Roba vencer a prova em $2 \mathrm{~h} 26 \mathrm{~min} 52 \mathrm{~s}$. Em Sydney-2000 e em Atenas-2004, a maratona foi vencida, respectivamente, pelas japonesas Naoko Takahashi (recordista olímpica), com o tempo de $2 \mathrm{~h} 23 \min 14 \mathrm{~s}$ e Mizuki Noguchi com o tempo de 2h26min20s. Em Pequim-2008, a romena Constantina Tomescu venceu a maratona em 2h26m44s (WIKIPEDIA, 2009).

Vale, ainda, mencionar que o recorde mundial de 2 h15min25s é de Paula Radcliffe, conquistado na Maratona de Londres, em 2003, enquanto que o melhor resultado brasileiro - até o momento - é o de 2h27min4s, conquistado por Carmen de Oliveira Furtado na Maratona de Boston, em 1994.

Em Jogos Olímpicos, poucas foram as brasileiras que conseguiram índice para participação na maratona. Segundo a Confederação Brasileira DE Atletismo (2010), foram elas: Eleonora Mendonça, que concluiu a maratona de Los Angeles-1984 na 44 colocação; Angélica de Almeida, 44a colocada em Seul-1988; Márcia Narloch que participou de três ediçôes olímpicas, conquistando a $17^{\mathrm{a}}$ colocação em 1992, a 39a colocação em 1996, embora, em 2004, não tenha concluído a prova; Janeth Mayal, que concluiu a maratona de Barcelona-1992, na $31^{\circ}$ colocação (LancellotTi, 1996, p.630); Carmem de Oliveira Furtado, que participou da maratona de Atlanta-1996, mas não a completou, enquanto Solange C. de Souza ficou com a $60^{\text {a }}$ colocação; Marlene T. dos Santos Furtado, que foi a única representante feminina na maratona de Atenas-2004, embora não tenha completado a prova e Marily dos Santos, a única representante na maratona em Pequim-2008, concluindo-a na $51^{\text {a }}$ colocação.

Quando comparada às provas que já eram disputadas nos Jogos Olímpicos da Antiguidade, como as corridas de velocidade, do lançamento do disco e do dardo, a prova da maratona pode ser considerada, em termos históricos, como um acontecimento recente, já que passou a integrar os Jogos Olímpicos somente na Era Moderna, em 1896 para os homens e, em 1984 para as mulheres. Nesses mais de 120 anos, porém, não foram poucas as emoções proporcionadas pelos atletas que se dispuseram a enfrentar o desafio de correr mais de $40 \mathrm{~km}$.

Mas, se esses são registros que fazem parte da história da maratona, é preciso se certificar se os professores de Educação Física, em especial os atuantes na escola, conhecem essa história a ponto de ensiná-la em suas aulas. Afinal, isso não é parte do conhecimento que deveria ser ensinado pela Educação Física?

Ao término dessa pesquisa, não restam dúvidas de que a história do esporte, no caso, da maratona, deveria integrar, como as das demais provas do atletismo, o conteúdo das aulas de Educação Física. Isso, certamente, contribuiria para que o atletismo, como um todo, fosse mais apreciado, conhecido e porque não, praticado. Resgatando a história de suas provas e trabalhando-a em suas aulas de Educação Física, por meio de vivências práticas voltadas a "reviver" essa história, de pesquisas e leituras sobre o tema, de filmes, exposiçôes de imagens e vídeos relacionados à prova ou de aulas teórico-práticas por exemplo, o professor, certamente, estaria contribuindo não apenas para a difusão dessa modalidade esportiva, mas para a difusão dessa história, ainda tão pouco conhecida.

\section{Notas}

1. Sobre o assunto, ver também: Prado (2007) e Matthiesen (2007), Freitas (2009), Ginciene (2009), Gomes (2010) e Sibila (2011).

2. Dados consultados em: CONFEDERAÇÃO BRASILEIRA DE ATLETISMO (CBAt). Nossos atletas olímpicos. Disponível em: <http://www.atletismo-gpbrasil.com.br/competicoes/rio2016/nossos_atletas.asp>. Acesso em: 09 nov. 2010. Apoio: PROGRAD/NE/UNESP. 


\section{Abstract \\ Records of the marathon in Olympic Games for diffusion in Physical Education classes}

Based on documentary research, the purpose of this study was to investigate the modifications for which marathon passed along the years, aiming to disseminate such knowledge, especially in physical education classes. Among the structural changes, athletes, records and curiosities about each edition of this Olympic event, it was found, for example, that inspired by a Greek legend, the marathon was included in the program of the Modern Olympic Games for males, in 1896 and for females, in 1984; it was performance in different distances and routes; new rules were introduced, such as the "Standard Scheiss." If these are some of the issues identified by this research, others should be evident, considering that the history of the sport is one of the contents that should be taught in physical education classes.

UnITERMs: Marathon; History of the sport; Physical education; Races.

\section{Resumen}

Los registros de la maratón en los Juegos Olímpicos para la difusión en las clases de Educación Física

Basado en una pesquisa documental, el objetivo de este estudio fue investigar los cambios por los cuales pasó el maratón en los últimos años con el objetivo de difundir este conocimiento, especialmente en clases de educación física. Entre los cambios estructurales, los atletas, las marcas y las curiosidades alrededor de cada una de las ediciones de este evento olímpico, se encontró, por ejemplo, que inspirado en una leyenda griega, el maratón fue incluido en la programación de los Juegos Olímpicos Modernos; el masculino en el año 1896, y el femenino en 1984. Fue disputado con diferentes distancias y recorridos, y se introdujeron nuevas normas, tales como las "Scheiss estándar." Si estas son algunas de las cuestiones señaladas por esta investigación, las demás también deben ser estudiadas, teniendo en cuenta que la historia de este deporte es uno de los contenidos que deben enseñarse en las clases de educación física.

Palabras Clave: Maratón; La historia del deporte; Educación física; Carrera.

\section{Referências}

BARBOSA, S.M. Jogos Olímpicos Modernos: esboço de história. O maior atleta do mundo. Rio de Janeiro: Mobral, 1979. BRASIL. Ministério da Educação e Cultura. Secretaria da Educação Física e Desportos. Confederação Brasileira de Atletismo. Atletismo: regras oficiais. Brasília: MEC,1981. . Atletismo: regras oficiais. Brasília: MEC,1984.

BRASIL. Ministério da Educação e do Desporto. Secretaria de Ensino Fundamental. Parâmetros Curriculares Nacionais: Área: Educação Física - terceiro e quarto ciclos do Ensino Fundamental. Brasília: MEC, 1998.

CERVO, A.L.; BERVIAN, P.A. Metodologia científica. 5. ed. São Paulo: Pearson Prentice Hall, 2002.

CONFEDERAÇÃO BRASILEIRA DE ATLETISMO (CBAt). Atletismo: regras oficiais. Brasília: MEC, s.d. . Atletismo: regras oficiais. Brasília: MEC, 1967-1968.

Regras oficiais de atletismo, 1995-1997. Rio de Janeiro: Sprint, 1995.

Regras oficiais de atletismo, 2000-2001. Rio de Janeiro: Sprint, 2000.

Regras oficiais de atletismo, 2001-2002. Rio de Janeiro: Sprint, 2001.

Regras oficiais de atletismo. São Paulo: Phorte, 2006.

Nossos atletas olímpicos. Disponível em: <http://www.atletismo-gpbrasil.com.br/competicoes/rio2016/nossos_atletas.asp>. Acesso em: 09 nov. 2010. 
D’ÂNGELO, R.A. Vanderlei Cordeiro de Lima: a maratona de uma vida. Rio de Janeiro: Casa da Palavra, 2007.

DARIDO, S.C.; RANGEL, I.C.A. (Eds.). Educação física na escola: implicações para a prática pedagógica. Rio de Janeiro: Guanabara Koogan, 2005.

ESPN. Mulheres corredoras. Disponível em: <http://www.espnbrasil.terra.com.br/wanderleideoliveira/post/106850_ MULHERES+CORREDORAS> . Acesso em: 24 out. 2010.

FAGANELLO, F.R. Análise dos livros de atletismo como subsídio para o seu ensino no campo escolar. 2008. $150 \mathrm{f}$. Dissertação (Mestrado em Ciências da Motricidade Humana) - Instituto de Biociências, Universidade Estadual Paulista, Rio Claro, 2008.

FREITAS, F.P.R. O salto com vara na escola: subsídios para o seu ensino a partir de uma perspectiva histórica. 2009. 189 f. Dissertação (Mestrado em Ciências da Motricidade Humana) - Instituto de Biociências, Universidade Estadual Paulista, Rio Claro, 2009.

GINCIENE, G. A evolução histórica da corrida de velocidade: um aprofundamento na prova dos 100 metros. 2009. 192 f. Trabalho de Conclusão de Curso (Bacharelado em Educação Física) - Instituto de Biociências, Universidade Estadual Paulista, Rio Claro, 2009.

GOMES, A.O. A evoluçáo histórica do lançamento do dardo: base para o ensino do atletismo em aulas de Educação Física. 2010. 104 f. Trabalho de conclusão de curso (Licenciatura em Educação Física) - Instituto de Biociências, Universidade Estadual Paulista, Rio Claro, 2010.

LANCELLOTTI, S. Olimpíada 100 anos. São Paulo: Círculo do Livro,1996.

LAWSON, G. World record breakers in track \& field athletics. Champaign: Human Kinetics, 1997.

MATTHIESEN, S.Q. Atletismo: teoria e prática. Rio de Janeiro: Guanabara Koogan, 2007.

MBPress. O atletismo em Jogos Olímpicos. Disponível em: <http://www. Esporte.hsw.uol.com.br/atletismo-jogosolimpicos.htm>. Acesso em: 22 out. 2010.

NOGUEIRA, S.C. 1896: Jogos Olímpicos de Atenas. Webrun: [s.ed.], 2002. Disponível em: <http://www.webrun.com. br/home/conteudo/noticias/index/id/262 >. Acesso em: 16 abr. 2009.

PAIOLI, C.C. Entre a trena e o cronômetro. São Paulo: Departamento de Esportes do Estado de São Paulo, 1949.

Lima e outras vitórias do atletismo brasileiro. Rio de Janeiro: Confederação Brasileira de Desportos, 1945.

PRADO, V.M Para além dos procedimentos técnicos: o atletismo em aulas de Educação Física. Motriz, Rio Claro, v.13, n.2, p.120-7, 2007.

RUBIO, K. Heróis olímpicos brasileiros. 2. ed. São Paulo: Zouk, 2004.

SÃO PAULO. Secretaria Estadual de Educação. Proposta Curricular do Estado de São Paulo: educação física. São Paulo: SEE, 2008a. (Caderno do Professor: Ensino Fundamental, 6a série, 1o bimestre).

. São Paulo: SEE, 2008b. (Caderno do Professor: Ensino Fundamental, 7a série, 1º bimestre).

São Paulo: SEE, 2008c. (Ensino Fundamental Ciclo II e Ensino Médio).

SIBILA, C.B. A história do salto triplo como subsídio para o seu ensino na escola. 2011. Trabalho de conclusão de curso (Licenciatura em Educação Física) - Instituto de Biociências, Universidade Estadual Paulista, Rio Claro, 2011.

WIKIPEDIA. Johnny Hayes. Disponível em: <http://pt.wikipedia.org/wiki/Johnny_Hayes>. Acesso em: 20 jun. 2010a.

Lista de campeóes olímpicos da maratona. Disponível em: <http://pt.wikipedia.org/wiki/Lista_de_ campe\%C3\%B5es_ol\%C3\%ADmpicos_da_maratona >. Acesso em: 20 jun. 2009.

Maratona. Disponível em: <http://www.pt.wikipedia.org/wiki/Maratona>. Acesso em: 20 out. $2010 \mathrm{~b}$.

\begin{tabular}{|c|c|}
\hline $\begin{array}{r}\text { ENDEREÇO } \\
\text { Sara Quenzer Matthiesen } \\
\text { Departamento de Educação Física - Instituto de Biociências } \\
\text { Universidade Estadual Paulista } \\
\text { Av. 24A, 1515 - Caixa Postal 199 } \\
\text { 13506-900 - Rio Claro - SP - BRASIL } \\
\text { e-mail: saraqm@rc.unesp.br }\end{array}$ & $\begin{array}{l}\text { Recebido para publicação: 21/ 07/ } 2011 \\
\text { Revisado: 02/ 03/2012 } \\
\text { Aceito: 18/ 05/2012 }\end{array}$ \\
\hline
\end{tabular}

